\title{
International Journal of Aging Research (DOI:10.28933/IJOAR)
}

\section{Fonoaudiology and Nutrition: a Multidisciplinary Look on the Elderly}

\section{Dysphagic}

\section{Souza Neta, H.H'; Paulo, A.M.F'; Veras, A.R.A.L ${ }^{1}$; Honorato, C.D.P ${ }^{3}$; Araújo, N.T.A'; Franco e} Santos, S.N.S ${ }^{1}$.

${ }^{1}$ Students of the Speech Therapy Course of the University Center of João Pessoa- UNIPÊ. ${ }^{2}$ Speech Therapist, Master, Teacher of the Speech Therapy Course at Faculty São Miguel - PE ${ }^{3}$ Student of the Nutrition Course of the Federal University of Paraíba-UFPB.

\section{ABSTRACT}

Introduction: In view of the inversion of the growth of the age pyramid in Brazil, where the increase in the elderly population has been highlighting, studies on this growing population and its specifications, such as incoordination in the act of swallowing food or saliva, are relevant. Functional, anatomical and physiological alterations resulting from senescence and associated pathologies directly interfere in swallowing, causing a damage. The swallowing deficit can lead to dysphagia, leading to malnutrition and dehydration in the elderly, due to a low caloric intake, food intake and even death. Since these aspects are impaired, it is necessary nutritional care and speech-language interventions on difficulties encountered at meals. Objective: To carry out a literature review through selected scientific articles about the importance of speech and hearing intervention in the elderly dysphagic. Methods: We conducted extensive research and selected articles published between 2013 and 2016, indexed in the SciELO, PubMed, MEDLINE and LILACS databases. The following keywords were selected in English: Dysphagia, Speech-Language Pathology, Elderly and Nutrition. Results: The elderly is prone to nutritional problems due to physiological and social factors, the occurrence of chronic disease, the use of various medications, feeding problems, chewing and swallowing, as well as changes in mobility with functional dependence. The swallowing impairment can result in dysphagia, since it is not alerted, the risk of aspiration is immense causing pneumonia and if untreated leading to death. The implantation of nutritional risk screening and risk of dysphagia specific for the elderly patient is extremely important aiming at the early diagnosis of nutritional status and deglutition so that there is adequate speech-language intervention. Conclusion: In this way, it is known the importance of the multiprofessional performance to result in the best quality of life Keywords Dysphagia; Speech therapy; Elderly; Nutrition.

*Correspondence to Author:

A. Veras, A.R.A.L

Speech Therapist, Master, Teacher of the Speech Therapy Course at Faculty São Miguel - PE

How to cite this article:

Souza Neta, H.H; Paulo, A.M.F; Veras, A.R.A.L; Honorato, C.D.P3; Araújo, N.T.A; Franco e Santos, S.N.S.Fonoaudiology and Nutrition: a Multidisciplinary Look on the Elderly Dysphagic. International Journal of Aging Research, 2018, 1:3

for such population, giving nutritional support, as well as the speech-language rehabilitation in the elderly dysphagic, aiming at it holistically. 